\title{
F-18 fluorodeoxyglucose positron emission tomography for differential diagnosis of pancreatic tumors
}

\author{
Masato Yoshioka ${ }^{1 *}$, Hiroshi Uchinami ${ }^{1}$, Go Watanabe ${ }^{1}$, Tsutomu Sato ${ }^{2}$, Satoshi Shibata ${ }^{3}$, Makoto Kume ${ }^{4}$, \\ Koichi Ishiyama ${ }^{5}$, Satoshi Takahashi ${ }^{5}$, Manabu Hashimoto ${ }^{5}$ and Yuzo Yamamoto ${ }^{1}$
}

\begin{abstract}
Positron emission tomography with 2-deoxy-2-[ ${ }^{[8}$ F]fluoro-D-glucose (FDG-PET) has been proven useful for differentiating pancreatic ductal cancer from mass-forming chronic pancreatitis. However, there are particular pancreatic tumors having various grades of malignancy such as intraductal papillary mucinous neoplasm (IPMN) or pancreatic neuroendocrine tumor. We examined whether the cut-off value of maximum standardized uptake value (SUV $\left.V_{\max }\right)$ determined by pancreatic ductal cancers is also applicable for other pancreatic tumors.

One hundred thirty six patients with pancreatic tumors underwent FDG-PET imaging. We first analyzed the cut-off value to differentiate pancreatic ductal cancers from mass-forming chronic pancreatitis. Secondly, we determined the cut-off value between malignant IPMN and benign IPMN. Thirdly, we computed a cut-off value between malignant pancreatic tumors and benign tumors irrespective of tumor type.

The optimal cut-off value to differentiate ductal cancers from mass-forming chronic pancreatitis was 2.5. The optimal cut-off value for differentiating malignant IPMN from benign IPMN was also 2.5, similar to that of reported studies. In all types of pancreatic tumors, the cut-off value was also 2.5. The accuracy for detecting malignancy was 93.4\% for all tumors.

In the FDG-PET study for pancreatic tumors, an SUV $V_{\max }$ of 2.5 would be justified as a cut-off value to differentiate malignant lesions.
\end{abstract}

Keywords: FDG-PET; SUV; Cut-off; IPMN; Non-ductal pancreatic cancer

\section{Background}

Owing the progress of imaging modalities such as abdominal ultrasonography (US) and computed tomography $(\mathrm{CT})$, accuracy in the diagnosis of pancreatic tumors has improved over the last decade. In pancreatic tumors, however, there are a variety of tumors such as ductal neoplasms, inflammatory and fibrotic tumors, and cystic tumors with malignant potentials of various degrees. Among them, intraductal papillary mucinous neoplasm (IPMN) and pancreatic neuroendocrine tumor ( $\mathrm{pNET}$ ) are the tumors in which it is difficult to distinguish malignant ones from benign ones preoperatively.

\footnotetext{
* Correspondence: masato@gipc.akita-u.ac.jp

${ }^{1}$ Department of Gastroenterological Surgery, Akita University Graduate

School of Medicine, 1-1-1 Hondo, Akita 010-8543, Japan

Full list of author information is available at the end of the article
}

Positron emission tomography using 2-deoxy-2-[ $\left[{ }^{18} \mathrm{~F}\right]$ fluoro-D-glucose (FDG-PET) is a noninvasive, useful imaging modality. Theoretical background is based on the difference of cellular glucose metabolism (Rempel et al. 1996). FDG-PET is reported as a valuable measure for diagnosing and staging various kinds of cancers (Delbeke 1999; Berberat et al. 1999; Kubota et al. 1990; Ishizu et al. 1994; Bares et al. 1994; Wahl et al. 1991; Jansson et al. 1995; Yoshioka et al. 2004). The usefulness of FDG-PET in differentiating pancreatic ductal cancer from massforming chronic pancreatitis has been reported. Maximum standardized uptake value $\left(\mathrm{SUV}_{\max }\right)$ is a common parameter for evaluating the uptake by a mass lesion semi-quantitatively. This value is defined as the radioactivity of the tissue divided by the total radioactivity of the probe isotope injected per body weight (Sadato et al. 1998). The cut-off values of $\mathrm{SUV}_{\max }$ in differentiating

\section{空}


pancreatic ductal cancer from mass-forming chronic pancreatitis have already been reported. Recommendable cutoff values for detecting malignancy of IPMN were previously reported in several studies (Tomimaru et al. 2010; Takanami et al. 2011; Hong et al. 2010), but the patient number of each study was very small as 29,16 and 31 patients, respectively.

In this study, as reported in other studies, we first analyzed the cut-off value of $\mathrm{SUV}_{\max }$ to differentiate patients with pancreatic ductal cancer from mass-forming chronic pancreatitis in our patient series. Secondly, similar analysis was done between the malignant and benign IPMNs, and the obtained cut-off value was compared with those in 3 published studies. Thirdly, we computed a cut-off value to differentiate the malignant pancreatic tumors from the benign tumors irrespective of tumor type including pNET, and examined whether this cut-off value was applicable for detecting pancreatic malignancy in general.

\section{Results}

Table 1 shows the number of patients and the $S U V_{\max }$ in the patients of each disease. The $S U V_{\max }$ in pancreatic ductal cancer and mass-forming chronic pancreatitis are illustrated in Figure 1a. There was a significant difference between these groups $(P<0.01)$. Figure $1 \mathrm{~b}$ demonstrates the ROC analysis of SUVs between ductal cancer and mass-forming chronic pancreatitis. The optimal SUV $\mathrm{max}_{\text {max }}$ to differentiate ductal cancer from massforming chronic pancreatitis was 2.5 , which was determined as the point of the curve farthest from the chance line. The areas divided by the curve were used to verify the performance of the analysis. The area under the curve was 0.982 , which showed this analysis was appropriate. When an $\mathrm{SUV}_{\max }$ of 2.5 was set as the cut-off value, only 4 of the ductal cancer lesions $\left(\mathrm{SUV}_{\max }=2.2\right.$, 1.9, 1.8 and 1.6, respectively) had an $\mathrm{SUV}_{\text {max }}$ below the cut-off value (false-negative). On the other hand, only one mass-forming chronic pancreatitis lesion $\left(\mathrm{SUV}_{\max }=\right.$ 5.3) had an $\mathrm{SUV}_{\max }$ above the cut-off value (false-positive). This patient has IgG4-related autoimmune pancreatitis (AIP). To summarize, when the cut-off value was set at 2.5 , sensitivity, specificity, positive predictive value, negative predictive value, and accuracy rate between ductal cancer and mass-forming chronic pancreatitis were shown in Table 2.

The $\mathrm{SUV}_{\max }$ in malignant IPMN (IPMC) and benign IPMN are illustrated in Figure 2a. There was a significant difference between these groups $(P<0.01)$. Figure $2 \mathrm{~b}$ illustrates the ROC analysis between IPMC and benign IPMN. The optimal SUV $\max$ to differentiate IPMC from benign IPMN was also 2.5. The area under the curve was 0.933 . When an $\mathrm{SUV}_{\max }$ of 2.5 was set as the cut-off value, 4 of the malignant IPMNs $\left(\mathrm{SUV}_{\max }=2.3,2.2,1.8\right.$ and 1.5, each) showed an $\mathrm{SUV}_{\text {max }}$ below the cut-off value (falsenegative). These 4 patients were all carcinoma in situ (CIS). There was no patient showing false-positive in the benign IPMN group.

Since the cut-off value to differentiate ductal cancer from mass-forming chronic pancreatitis was the same as the cut-off value to differentiate IPMC from benign IPMN (that is 2.5), we unified the data of all malignant tumors and all benign tumors including pNETs-pNETs were not suitable for independent analysis due to their small number of cases-and re-computed a cut-off value to discriminate between malignant and benign tumors of the pancreas. The $\mathrm{SUV}_{\max }$ in all malignant tumors and all benign tumors was illustrated in Figure 3a. There was a significant difference between these groups $(P<0.01)$. The optimal $\mathrm{SUV}_{\max }$ to differentiate all malignant tumor lesions from all benign tumor lesions was exactly 2.5 (Figure $3 b$ ). The area under the curve was 0.957 . When an $\mathrm{SUV}_{\max }$ of 2.5 was set as the cut-off value, only 8 of the malignant tumors (4 ductal cancers and 4 IPMCs

Table 1 The mean and range of maximum SUV in patients of each disease

\begin{tabular}{|c|c|c|c|}
\hline Disease & Malignant/Benign & No. of Patients & Mean SUV $\max$ (Range) \\
\hline Pancreatic ductal cancer & Malignant & 80 & $5.4(1.6-11.8)$ \\
\hline Mass-forming chronic pancreatitis & Benign & 10 & $2.0(1.2-5.3)$ \\
\hline Intraductal papillary mucinous carcinoma & Malignant & 18 & $5.5(1.5-13.8)$ \\
\hline Intraductal papillary mucinous neoplasm & Benign & 12 & $1.7(1.1-2.3)$ \\
\hline Neuroendocrine carcinoma & Malignant & 4 & \\
\hline Non-functioning islet cell carcinoma & & 4 & $9.0(3.3-13.8)$ \\
\hline Neuroendocrine tumor & Benign & 12 & \\
\hline Insulinoma & & 7 & $1.6(1.1-2.0)$ \\
\hline Glucagonoma & & 2 & $1.9(1.8-2.0)$ \\
\hline Gastrinoma & & 1 & 1.8 \\
\hline Non-functioning islet cell tumor & & 2 & $2.2(1.9-2.4)$ \\
\hline
\end{tabular}



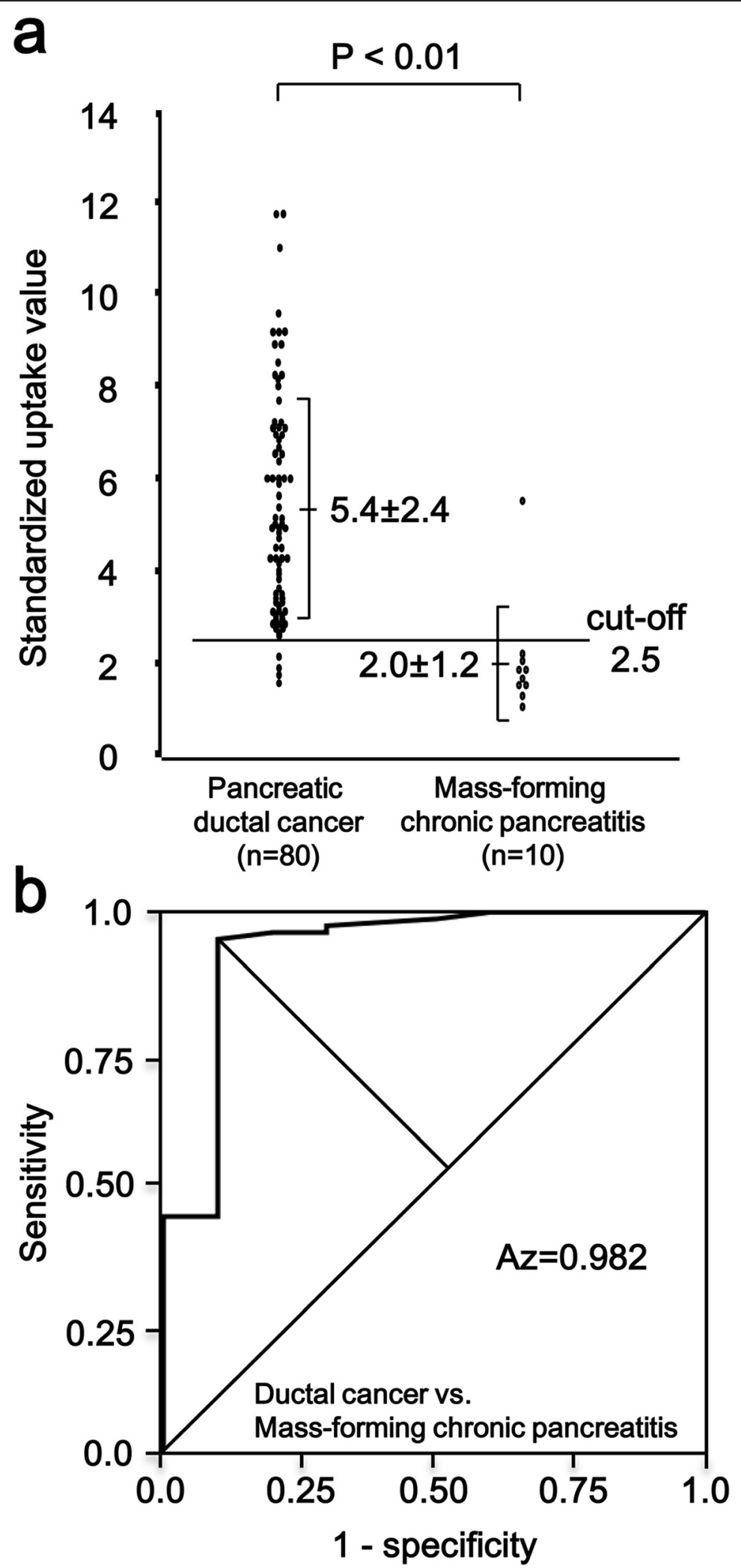

Figure 1 (See legend on next page.) 
(See figure on previous page.)

Figure 1 Maximum standardized uptake value $\left(S U V_{\max }\right)$ in pancreatic ductal cancer and mass-forming chronic pancreatitis. (a) There is a significant difference in SUV $\max$ between pancreatic ductal cancer and mass-forming chronic pancreatitis non-parametrically, $P<0.01$. The number in each column is the mean SUV $\max \pm$ standard deviation. (b) Receiver operating characteristic curve in pancreatic ductal cancer and mass-forming chronic pancreatitis. The area under the curve is 0.982 .

[CIS]) had an $\mathrm{SUV}_{\max }$ below the cut-off value (falsenegative). On the other hand, in all benign tumors, only one patient (IgG4-related AIP) showed false-positive. Sensitivity, specificity and accuracy rate were $92.2 \%$, 97.1\% and $93.4 \%$, respectively (Table 2). As to pNET, $\mathrm{SUV}_{\max }$ of four malignant non-functioning islet cell tumors were all above this cut-off value of 2.5 (SUV = 13.8, 12.5, 6.2 and 3.3); and all of 12 benign pNETs showed $\mathrm{SUV}_{\max }$ below this cut-off value, although the case number is limited.

\section{Discussion}

In the differential diagnosis between pancreatic ductal cancer and mass-forming chronic pancreatitis, high accuracy of FDG-PET-greater than 85\%-has already been noted (Inokuma et al. 1995; Nakamoto et al. 1999; Imdahl et al. 1999; Nitzsche et al. 2002). Usually, increased FDG uptake by the tumor is visually assessed in comparison with that by surrounding tissues. This classical method is, however, sometimes not useful for differential diagnosis, especially when the tumors are not sufficiently large. In contrast, an $\mathrm{SUV}_{\max }$ offering a semi-quantitative analysis is more advantageous. In this study, the cut-off value of $\mathrm{SUV}_{\max }$ for differentiating pancreatic ductal cancer from mass-forming chronic pancreatitis was 2.5. This value was comparable with those obtained in other studies (Nakamoto et al. 2000; Delbeke et al. 1999), indicating that a cut-off value of 2.5 for this purpose was credible. On the other hand, there were several studies dealing about the usefulness of FDG-PET for differential diagnosis between malignant and benign IPMN (Tomimaru et al. 2010; Takanami et al. 2011; Hong et al. 2010; Sperti et al. 2001, 2005, 2007; Mansour et al. 2006; Tann et al. 2007; Pedrazzoli et al. 2011). But some studies, in addition to IPMNs, included other cystic tumors, ductal cancer and histologically undetermined tumors as well (Sperti et al. 2001, 2005, 2007; Mansour et al. 2006; Tann et al. 2007;
Pedrazzoli et al. 2011). There were only 3 studies that calculated the accuracy within genuine IPMNs (Tomimaru et al. 2010; Takanami et al. 2011; Hong et al. 2010). Tomimaru et al. first reported the usefulness of $S U V_{\max }$ in differentiating malignant and benign IPMNs (Tomimaru et al. 2010). In their study, patient number was 14 with malignancy and 15 with benign IPMNs. They set the best cut-off value as 2.5 with a high accuracy of $96 \%$. Takanami et al. reported the second study (Takanami et al. 2011). In their report, there were 9 malignant IPMNs and 7 benign IPMNs (total 16 patients), and a cut-off value of 2.3 was the best with a high accuracy of $87.5 \%$. Thirdly, Hong et al. described that the diagnostic accuracy of a cut-off value using $\mathrm{SUV}_{\max } 2.5$ was as high as $96 \%$ in 31 patients (Hong et al. 2010). Regrettably, they merely adopted this cut-off value from other reports that dealt with miscellaneous types of cystic tumors (Sperti et al. 2005, 2007; Mansour et al. 2006; Tann et al. 2007) and skipped the process of statistical estimation. They gave no explanation as to why they used an $\mathrm{SUV}_{\max }$ of 2.5 as a cut-off value. In contrast, the former two reports are distinguishing because they determined their cut-off values by ROC analysis. However, even in these reports, the numbers of patient were only 29 and 16, respectively. Since the incidence of IPMN is relatively small in comparison with ductal cancer, there is a limitation in the study performed by a single institution. Indeed, in our study also, the patient number is 30 and still small. Nevertheless, the cut-off values independently determined by these three studies were consistent. Hence, the cut-off value 2.5 seems to be acceptable for differentiating IPMC from benign IPMN.

Meanwhile, in regard to pNET, there is no study dealing with the cut-off value of $\mathrm{SUV}_{\max }$ in differentiating malignancy because patient number is further small. However, interestingly, PET scan in our study detected high FDG uptake above 2.5 in all 4 patients with nonfunctioning islet cell carcinoma, and below 2.5 in all benign pNETs. Although we cannot draw a definitive

Table 2 The efficacy of the cut-off value in differential diagnosis

\begin{tabular}{|c|c|c|c|c|c|c|c|}
\hline & Cut-off (SUV max $\left._{\text {max }}\right)$ & Az value & SEN (\%) & SPE (\%) & PPV (\%) & NPV (\%) & ACC (\%) \\
\hline Pancreatic ductal cancer vs. Mass-forming chronic pancreatitis & 2.5 & 0.982 & 95.0 & 90.0 & 98.7 & 69.2 & 94.4 \\
\hline Malignant IPMN vs. Benign IPMN & 2.5 & 0.933 & 77.8 & 100 & 100 & 75.0 & 86.7 \\
\hline All malignant tumors vs. All benign tumors & 2.5 & 0.957 & 92.2 & 97.1 & 98.9 & 80.1 & 93.4 \\
\hline
\end{tabular}

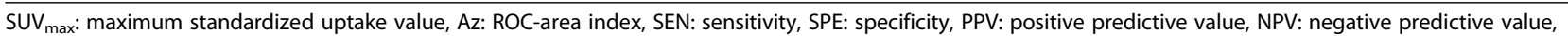
ACC: accuracy, IPMN: intraductal papillary mucinous neoplasm. 


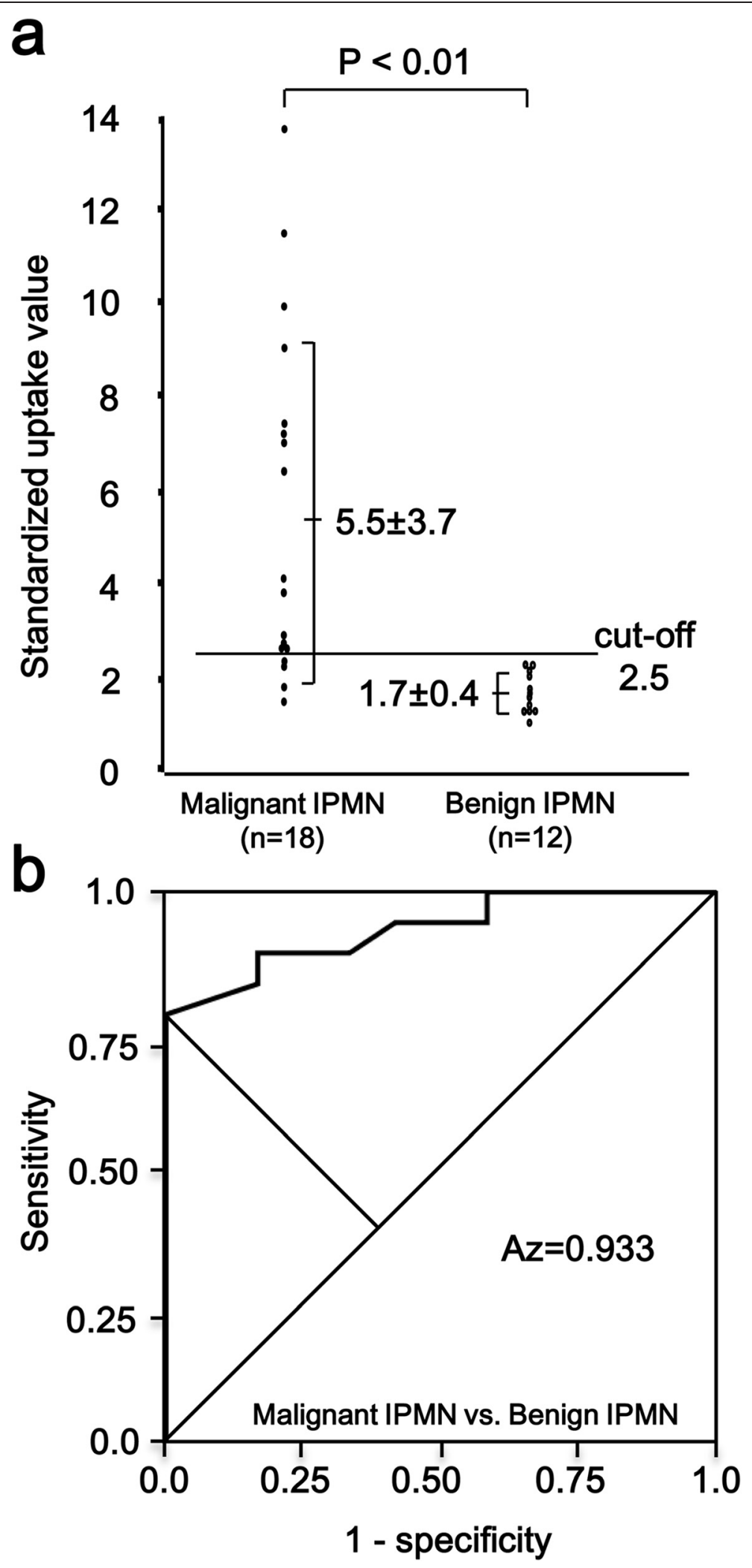

Figure 2 Maximum standardized uptake value $\left(\mathrm{SUV}_{\mathrm{max}}\right)$ in malignant intraductal papillary mucinous neoplasm (IPMN) and benign IPMN. (a)

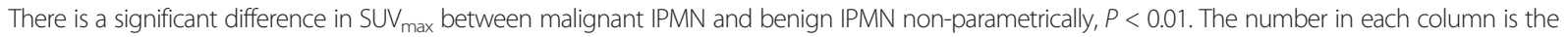
mean SUV $V_{\max } \pm$ standard deviation. (b) Receiver operating characteristic curve in malignant IPMN and benign IPMN. The area under the curve is 0.933 . 

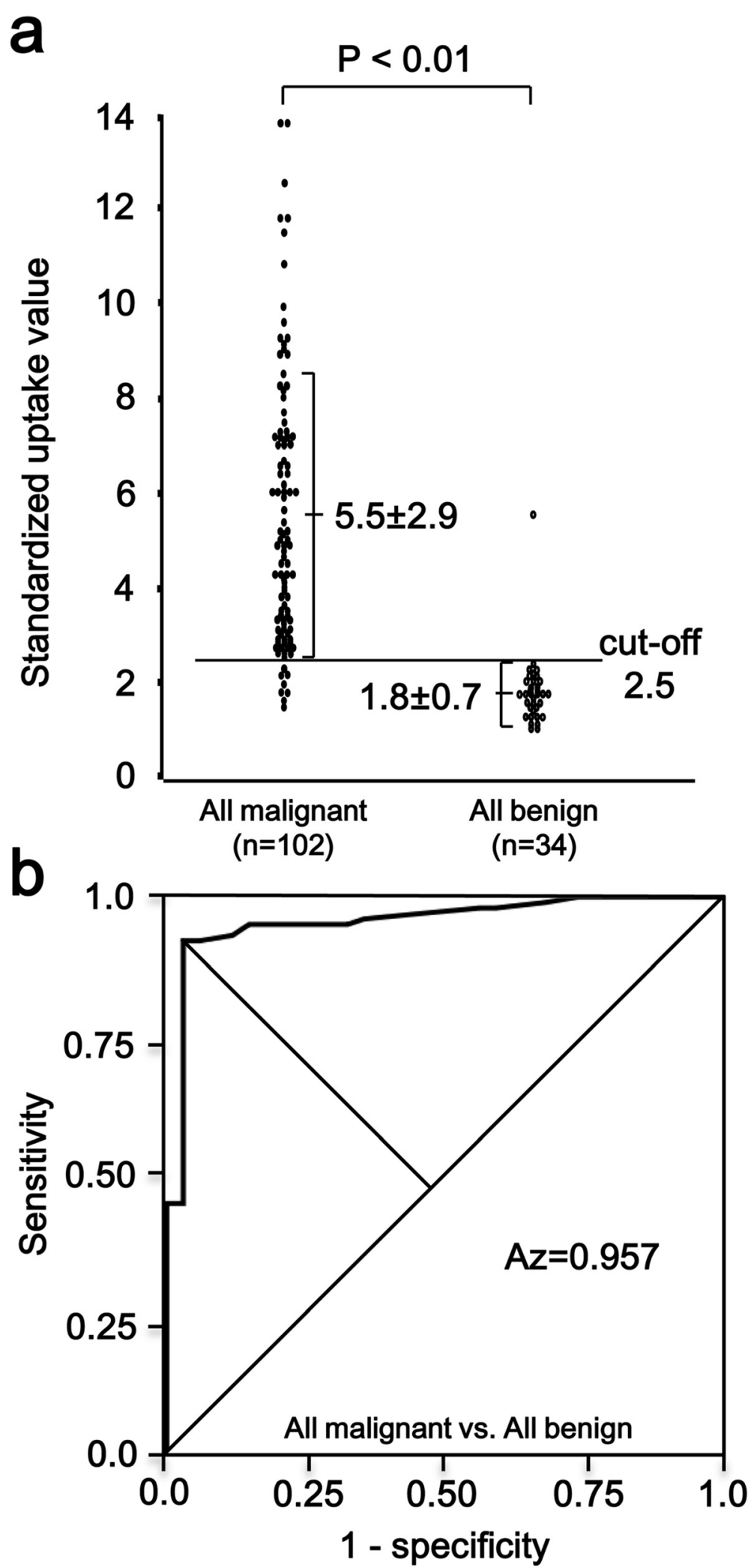

Figure 3 Maximum standardized uptake value $\left(S_{U} V_{\text {max }}\right)$ in all malignant tumors and all benign tumors. (a) There is a significant difference in $S \mathrm{SV}_{\max }$ between all malignant tumors and all benign tumors non-parametrically, $P<0.01$. The number in each column is the mean $S U V_{\text {max }} \pm$ standard deviation. (b) Receiver operating characteristic curve in all malignant tumors and all benign tumors. The area under the curve is 0.957. 
conclusion, it is likely that cut-off value of 2.5 would be useful even for pNET. Further study is intriguing.

We reviewed 8 false-negative lesions in malignancies (4 ductal cancers and 4 IPMCs) and one false-positive lesion in mass-forming chronic pancreatitis in detail. We cannot explain the reason why 4 patients $(5.0 \%)$ having ductal cancer showed false-negative $\left(\mathrm{SUV}_{\max }=2.2,1.9\right.$, 1.8 and 1.6, each) because there was no difference between these 4 tumors and others concerning the tumor size and histological differentiation. Four of 18 patients $(22.2 \%)$ having IPMC showed false-negative $\left(\mathrm{SUV}_{\max }=\right.$ 2.3, 2.2, 1.8 and 1.5, each). These tumors were all CIS. To detect the CIS preoperatively is extremely difficult, and FDG-PET would regard CIS as benign lesion. There was only one false-positive lesion in mass-forming chronic pancreatitis. This case had IgG4-related AIP. If serum IgG4 level or other markers that indicate autoimmunity had been elevated preoperatively, we could suspect IgG4-related AIP in the first place. However, in our patient, these markers were all within normal limits. In this way, there are patients showing that serum IgG4 and other markers are within normal limits. In these cases, preoperative diagnosis is not easy. As to FDGPET for IgG4-related AIP, some case reports are published, but the study of FDG-PET in differential diagnosis of IgG4-related AIP has not been performed yet because patient number is extremely limited for submitting analysis. Kamisawa et al. compared the $\mathrm{SUV}_{\max }$ of autoimmune pancreatitis and pancreatic cancer (Kamisawa et al. 2010). They showed that there was no significant

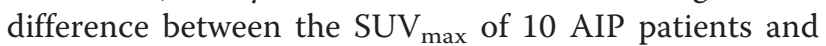
that of 14 pancreatic cancer patients. This is only one study and preliminary, but the result would suggest the difficulty in differential diagnosis of AIP using FDG-PET. Further prospective study with a larger number of cases is encouraged.

In the past 15 years, new technologies have been developed. With regard to tracers, ${ }^{18} \mathrm{~F}$ labelled deoxyfluorothymidine has been tested for detecting pancreatic cancers (Herrmann et al. 2012). For pNET, somatostatin analogues (TETA-Y3-TATE, DOTA-Tyr3-octreotide) have been labelled with ${ }^{64} \mathrm{Cu}$ or ${ }^{68} \mathrm{Ga}$ (Lewis et al. 1999; Gabriel et al. 2007). For detecting insulinoma, specific probe targeting glucagon-like peptide-1 receptor has been developed (Brom et al. 2010; Wild et al. 2010, Eriksson et al. 2014). As a new imaging modality, PET-MRI was also developed and tested for detecting the gastroenteropancreatic NET (Beiderwellen et al. 2013). However, these new tracers and machines have been used in trial only at some limited institutions, and thus their usefulness is still under evaluation. It will take a little time before these methods become widespread in the hospitals where ordinary patients will access. The most useful strategy at present seems to be FDG-PET/CT.

\section{Conclusions}

This study suggested a good potential of FDG-PET in differentiating malignancy also in pancreatic tumors other than ductal cancer. Calculation of $S_{U V} V_{\max }$ would be greatly helpful for differential diagnosis when the malignancy is uncertain in pancreatic lesions despite the full use of conventional imaging modalities. It was indicated that an $\mathrm{SUV}_{\max }$ of 2.5 would be justified as a cutoff value for malignant pancreatic tumors in general, as it is for ductal cancer.

\section{Materials and methods \\ Patients}

From October 2001 to December 2014, 136 patients (76 males and 60 females; mean age, 66 years old; age range $26-88$ years old) were diagnosed as having pancreatic tumors by US, CT, and magnetic resonance imaging (MRI) in our department. All of them underwent FDGPET. The diagnosis was histologically proven and the final diagnoses were 80 pancreatic ductal cancers, 10 mass-forming chronic pancreatitis, 18 intraductal papillary mucinous carcinoma (IPMC), 12 benign IPMN, 4 malignant pNETs (non-functioning islet cell carcinoma) and 12 benign pNETs ( 7 insulinoma, 2 glucagonoma, 1 gastrinoma and 2 non-functioning islet cell tumor). The research protocol of this study was approved by the Ethics Committee of Akita University Graduate School of Medicine (No.1223), and each patient gave written informed consent before enrollment in the study.

\section{FDG-PET}

FDG-PET studies were performed either with Headtome V (Shimadzu Co., Kyoto, Japan) or with PET-CT scanner of Discovery ST Elite 16 (GE healthcare, Milwaukee, WI, USA). Patients having pancreatic cancer and/or chronic pancreatitis often show hyperglycemia. Because the uptake of ${ }^{18}$ F-FDG by the tumors is reduced in hyperglycemic status, the guideline for FDG-PET/CT recommends that examination be performed under the blood glucose level lower than 150-200 mg/dl (Delbeke et al. 2006). All patients enrolled in this study fasted for 6 hours before examination and were checked for their blood glucose level just before examination. When the blood glucose level was greater than $150 \mathrm{mg} / \mathrm{dl}$, we rescheduled the examination. The images were acquired first at 60 minutes after ${ }^{18}$ F-FDG of approximately 185 $\mathrm{MBq}$ injection. CT scanning was performed with $120 \mathrm{kV}$ tube voltage and Auto $\mathrm{mA}$. Images were reconstructed with a slice thickness of $3.75 \mathrm{~mm}$. Neither intravenous nor oral contrast materials were used. Acquisitions were performed in 3-dimensional mode, $3 \mathrm{~min} /$ bed position. Data were reconstructed using VUE Point Plus; ordinary Poisson OSEM (Ordered Subset Expectation Maximization) with 10 subsets and 2 iterations. A region of interest (ROI) 
was designated at the site of maximal accumulation within the mass lesion. The maximal radioactivity of the ROI was determined. FDG uptake was calculated as SUV according to the following formula (constant factor $=10$, calibration factor $\left.(C F)=7.40 \times 10^{6}\right)$ :

$$
\mathrm{SUV}_{\max }=\frac{\mathrm{ROI}(\mathrm{cps} / \mathrm{g}) \times \text { constant factor }}{\text { injection dose }(\mathrm{mCi}) / \text { bpdy weight }(\mathrm{g}) \times(\mathrm{cps} / \mathrm{mCi})}
$$

\section{Statistical analysis}

The data presented were expressed as means \pm standard deviation (S.D.) The statistical analysis of $\mathrm{SUV}_{\max }$ between the groups was performed by Mann-Whitney $U$ test. A $P$ value of $<0.05$ was considered statistically significant. The $\mathrm{SUV}_{\max }$ threshold (cut-off value) was determined by the receiver operating characteristic (ROC) analysis. ROC analysis was performed using calculation software IBM SPSS. The performance of the ROC analysis was verified by the ROC-area index Az. The cut-off point was determined by the Youden Index.

\section{Competing interest}

The authors declare that they have no competing interest.

\section{Authors' contributions}

MY designed the study, analyze data, and wrote a manuscript; HU, GW, TS, SS and MK acquired and analyzed the patient data; KI, ST and MH measured the SUV of FDG-PET and analyzed data, YY wrote a manuscript and performed the total organization of this study. All authors read and approved the final manuscript.

\section{Author details}

'Department of Gastroenterological Surgery, Akita University Graduate School of Medicine, 1-1-1 Hondo, Akita 010-8543, Japan. ${ }^{2}$ Department of Surgery, Akita City Hospital, Akita 010-0933, Japan. ${ }^{3}$ Department of Surgery, Honjo Daiichi Hospital, Honjo, Akita 015-8567, Japan. ${ }^{4}$ Department of Surgery, Murakami Memorial Hospital, Asahi University, Gifu 500-8523, Japan. ${ }^{5}$ Department of Radiology, Akita University Graduate School of Medicine, 1-1-1 Hondo, Akita 010-8543, Japan.

Received: 27 January 2015 Accepted: 20 March 2015 Published online: 31 March 2015

\section{References}

Bares R, Klever P, Hauptmann S, Hellwig D, Fass J, Cremerius U, Schumpelick V, Mittermayer C, Büll U (1994) F-18 fluorodeoxyglucose PET in vivo evaluation of pancreatic glucose metabolism for detection of pancreatic cancer. Radiology 192:79-86

Beiderwellen KJ, Poeppel TD, Hartung-Knemeyer V, Buchbender C, Kuehl H, Bockisch A, Lauenstein TC (2013) Simultaneous 65Ga-DOTATOC PET/MRI in patients with gastroenteropancreatic neuroendocrine tumors: initial results. Invest Radiol 48:273-279

Berberat P, Freiss H, Kashiwagi M, Berger HG, Büchler MW (1999) Diagnosis and staging of pancreatic cancer by positron emission tomography. World J Surg 23:882-887

Brom M, Oyen WJG, Joosten L, Gotthardt M, Boerman OC (2010) 68Ga-labelled exendin-3, a new agent for the detection of insulinomas with PET. Eur J Nucl Med Mol Imaging 37:1345-1355

Delbeke D (1999) Oncological applications of FDG-PET imaging. J Nucl Med 40:1706-1715

Delbeke D, Rose DM, Chapman WC, Pinson CW, Wright JK, Beauchamp RD, Shyr Y, Leach SD (1999) Optimal interpretation of FDG PET in the diagnosis, staging and management of pancreatic carcinoma. J Nucl Med 40:1784-1791

Delbeke D, Coleman RE, Guiberteau MJ, Brown ML, Royal HD, Siegel BA, Townsend DW, Berland LL, Parker JA, Hubner K, Stabin MG, Zubal G,
Kachelriess M, Cronin V, Holbrook S (2006) Procedure guideline for tumor imaging with ${ }^{18}$ F-FDG PET/CT 1.0. J Nucl Med 47:885-895

Eriksson O, Velikyan I, Selvaraju RK, Kandeel F, Johansson L, Antoni G, Eriksson B, Sörensen J, Korsgren O (2014) Detection of metastatic insulinoma by positron emission tomography with [(68)ga]exendin-4-a case report. J Clin Endocrinol Metab 99:1519-1524

Gabriel M, Decristoforo C, Kendler D, Dobrozemsky G, Heute D, Uprimny C, Kovacs P, Von Guggenberg E, Bale R, Virgolini IJ (2007) 68Ga-DOTA-Tyr3octreotide PET in neuroendocrine tumors: comparison with somatostatin receptor scintigraphy and CT. J Nucl Med 48:508-518

Herrmann K, Erkan M, Dobritz M, Schuster T, Siveke JT, Beer AJ, Wester HJ, Schmid RM, Friess H, Schwaiger M, Kleeff J, Buck AK (2012) Comparison of 3'-deoxy-3'-[18F] fluorothymidine positron emission tomography (FLT PET) and FDG PET/CT for the detection and characterization of pancreatic tunours. Eur J Nucl Med Mol Imaging 39:846-851

Hong HS, Yun M, Cho A, Choi JY, Kim MJ, Kim KW, Choi YJ, Lee JD (2010) The utility of F-18 FDG PET/CT in the evaluation of pancreatic intraductal papillary mucinous neoplasm. Clin Nucl Med 35:776-779

Imdahl A, Nitzsche E, Krautmann F, Högerle S, Boos S, Einert A, Sontheimer J, Farthmann EH (1999) Evaluation of positron emission tomography with 2-[18F]fluoro-2-deoxy-D-glucose for the differentiation of chronic pancreatitis and pancreatic cancer. Br J Surg 86:194-199

Inokuma T, Tamaki N, Torizuka T, Fujita T, Magata Y, Yonekura Y, Ohshio G, Imamura M, Konishi J (1995) Value of fluorine-18-fluorodeoxyglucose and thallium-201 in the detection of pancreatic cancer. J Nucl Med 36:229-235

Ishizu K, Sadato N, Yonekura Y, Nishizawa S, Magata Y, Tamaki N, Tsuchida T, Okazawa H, Tanaka F, Miyatake S, Ishikawa M, Kikuchi H, Konishi J (1994) Enhanced detection of brain tumors by [18F]fluorodeoxyglucose PET with glucose loading. J Comput Assist Tomogr 18:12-15

Jansson T, Westlin JE, Ahlstrom H, Lija A, Langstrom B, Bergh J (1995) Positron emission tomography studies in patients with locally advanced and/or metastatic breast cancer: A method for early therapy evaluation? J Clin Oncol 13:1470-1477

Kamisawa T, Takum K, Anjiki H, Egawa N, Kurata M, Honda G, Tsuruta K (2010) FDG-PET/CT findings of autoimmune pancreatitis. Hepatogastroenterology $57: 447-450$

Kubota K, Matsuzawa T, Fujiwara T, Ito M, Hatazawa J, Ishiwata K, Iwata R, Ido T (1990) Differential diagnosis of lung tumor with positron emission tomography: a prospective study. J Nucl Med 31:1927-1932

Lewis JS, Srinivasan A, Schmidt MA, Anderson CJ (1999) In vitro and in vivo evaluation of 64Cu-TETA-Tyr3-octreotate. A new somatostatin analog with improved target tissue uptake. Nucl Med Biol 26:267-273

Mansour JC, Schwartz L, Pandit-Taskar N, D'Angelica M, Fong Y, Larson SM, Brennan MF, Allen PJ (2006) The utility of F-18 fluorodeoxyglucose whole body PET imaging for determining malignancy in cystic lesions of the pancreas. J Gastrointest Surg 10:1354-1360

Nakamoto Y, Higashi T, Sakahara H, Tamaki N, Kogire M, Imamura M, Konishi J (1999) Contribution of PET in the detection of liver metastasis from pancreatic tumours. Clin Radiol 54:248-252

Nakamoto Y, Higashi T, Sakahara H, Tamaki N, Kogire M, Doi R, Hosotani R, Imamura M, Konishi J (2000) Delayed (18)F-fluoro-2-deoxy-D-glucose positron emission tomography scan for differentiation between malignant and benign lesions in the pancreas. Cancer 89:2547-2554

Nitzsche EU, Hoegerle S, Mix M, Brink I, Otte A, Moser E, Imdahl A (2002) Non-invasive differentiation of pancreatic lesions: is analysis of FDG kinetics superior to semiquantitative uptake value analysis? Eur J Nuc Med Mol Imaging 29:237-242

Pedrazzoli S, Sperti C, Pasquali C, Bissoli S, Chierichetti F (2011) Comparison of International Consensus Guidelines versus 18-FDG PET in detecting malignancy of intraductal papillary mucinous neoplasm of the pancreas. Ann Surg 254:971-976

Rempel A, Mathupala SP, Griffin CA, Hawkins AL, Pederson PL (1996) Glucose metabolism in cancer cells: amplification of the gene encoding type II hexokinase. Cancer Res 56:2468-2471

Sadato N, Tsuchida T, Nakaumra S, Waki A, Uematsu H, Takahashi N, Hayashi N, Yonekura Y, Ishii Y (1998) Non-invasive estimation of the net influx constant using the standardized uptake value for quantification of FDG uptake of tumours. Eur J Nucl Med 25:559-564

Sperti C, Pasquali C, Chierichetti F, Liessi G, Ferlin G, Pedrazzoli S (2001) Value of 18-fluorodeoxyglucose positron emission tomography in the management of patients with cystic tumors of the pancreas. Ann Surg 234:675-680 
Sperti C, Pasquali C, Decet G, Chierichetti F, Liessi G, Padrazzoli S (2005)

F-18-fluorodeoxyglucose positron emission tomography in differentiating malignant from benign pancreatic cysts: a prospective study. J Gastrointest Surg 9:22-29

Sperti C, Bissoli S, Pasquali C, Frison L, Liessi G, Chierichetti F, Pedrazzoli S (2007) 18-fluorodeoxyglucose positron emission tomography enhances computed tomography diagnosis of malignant intraductal papillary mucinous neoplasm of the pancreas. Ann Surg 246:932-939

Takanami K, Hiraide T, Tsuda M, Nakamura Y, Kaneta T, Takase K, Fukuda H, Takahashi S (2011) Additional value of FDG PET/CT to contrast-enhanced CT in the differentiation between benign and malignant intraductal papillary mucinous neoplasms of the pancreas with mural nodules. Ann Nucl Med 25:501-510

Tann M, Sandrasegaran K, Jennings SG, Skandarajah A, Mchenry L, Schmidt CM (2007) Positron-emission tomography and computed tomography of cystic pancreatic masses. Clin Radiol 62:745-751

Tomimaru Y, Takeda Y, Tatsumi M, Kim T, Kobayashi S, Marubashi S, Eguchi H, Tanemura M, Kitagawa T, Nagano H, Umeshita K, Wakasa K, Doki Y, Mori M (2010) Utility of 2-[18F] fluoro-2-deoxy-D-glucose positron emission tomography in differential diagnosis of benign and malignant intraductal papillary-mucinous neoplasm of the pancreas. Oncol Rep 24:613-620

Wahl RL, Cody RL, Hutchins GD, Mudgett EE (1991) Primary and metastatic breast carcinoma: initial clinical evaluation with PET with the radiolabeled glucose analogue 2-[F-18]-fluoro-2-deoxy D-glucose. Radiology 179:765-770

Wild D, Wicki A, Mansi R, Béhé M, Keil B, Bernhardt P, Christofori G, Ell PJ, Mäcke HR (2010) Exendin-4-based radiopharmaceuticals for glucagonlike peptide-1 receptor PET/CT and SPECT/CT. J Nucl Med 51:1059-1067

Yoshioka M, Sato T, Furuya T, Shibata S, Andoh H, Asanuma Y, Hatazawa J, Shimosegawa E, Koyama K, Yamamoto Y (2004) Role of positron emission tomography with 2-deoxy-2-[18 F]fluoro-D-glucose in evaluating the effects of arterial infusion chemotherapy and radiotherapy on pancreatic cancer. J Gastroenterol 39:50-55

\section{Submit your manuscript to a SpringerOpen ${ }^{\circ}$ journal and benefit from:}

- Convenient online submission

- Rigorous peer review

- Immediate publication on acceptance

- Open access: articles freely available online

- High visibility within the field

- Retaining the copyright to your article

Submit your next manuscript at $\gg$ springeropen.com 